\title{
Perspective ways to improve the strength properties and resistance to hydrogen induced cracking of low-alloy pipe steels
}

\author{
Alexey Kholodnyi ${ }^{1 *}$, Ivan Shabalov ${ }^{1,2}$, Yury Matrosov ${ }^{1}$, and Valery Velikodnev ${ }^{3}$ \\ ${ }^{1}$ I.P. Bardin Central Research Institute for Ferrous Metallurgy, 105005 Moscow, Russia \\ ${ }^{2}$ Association of Pipe Manufacturers, 115088 Moscow, Russia \\ ${ }^{3}$ Center for Examination of Pipeline Systems and Engineering, 127051 Moscow, Russia
}

\begin{abstract}
The perspective ways to improve the strength properties and resistance to hydrogen induced cracking (HIC) of low-alloy pipe steels were established. The possibility to improve the strength properties and resistance to $\mathrm{HIC}$ of plates due the additive of $0.15 \%$ molybdenum while decreasing finish temperature of accelerated cooling from 560 to $420^{\circ} \mathrm{C}$ was found. The influence of heating in the $\alpha-,(\alpha+\gamma)-$ and $\gamma$ regions followed by air cooling on the mechanical properties and resistance to HIC of various alloying systems pipe steels plates was studied. The possibility of increasing the strength while maintaining the resistance to HIC of plates by tempering at heating in the $\alpha$-region was shown
\end{abstract}

\section{Introduction}

The presence of $\mathrm{H}_{2} \mathrm{~S}$ impurities in the transported natural gas and oil can lead to sudden or delayed destruction of pipes by the mechanisms of corrosion cracking. Electrochemical corrosion with the participation of $\mathrm{H}_{2} \mathrm{~S}$ and $\mathrm{H}_{2} \mathrm{O}$ produces atomic hydrogen on the surface of the pipe, which can be absorbed by the steel. Hydrogen atoms are present in the steel as impurity implants in the crystal lattice or accumulate on non-metallic inclusions, grain boundaries and phases, in pores where they can pass into the molecular form $\left(\mathrm{H}_{2}\right)$, which has a significant volume. This leads to high internal tensile stresses and the formation of cracks which spread through hard and brittle structures.

The operational reliability of pipelines under the conditions of exposure to aggressive $\mathrm{H}_{2} \mathrm{~S}$-containing "sour" environment, along with strength properties and cold resistance, is provided by increasing resistance to hydrogen induced cracking (HIC). Currently, there is a tendency to increase the requirements for strength characteristics and resistance to corrosion cracking of pipes. Therefore, the search for perspective ways to improve the properties of low-alloy pipe steels resistant to HIC is an important scientific and production task [1].

\section{Molybdenum alloying}

The role of molybdenum in the formation of the structure and properties of high-strength low-alloy pipe steels manufactured by the technology of thermomechanical processing is well-known. Molybdenum is used in pipe steels for the achievement of high strength properties for steels of X80 and higher grades or for the production of thick plates $(\geq 25 \mathrm{~mm}$ ) for offshore pipelines. It was of interest to study the possibility of simultaneous enhancement of strength properties and realization of high cracking resistance of the plates from pipe steels in hydrogen sulfidecontaining media by using small molybdenum additions.

\subsection{Mechanical properties}

The effect of $0.15 \%$ molybdenum on the microstructure and properties of microalloyed pipe steel was studied on the two test steels with the same contents of basic chemical elements: $\quad 0.06 \% \mathrm{C} ; \quad 0.90-0.95 \% \mathrm{Mn}$; $0.70 \%(\mathrm{Cr}+\mathrm{Ni}+\mathrm{Cu}) ; \quad 0.120 \%(\mathrm{Nb}+\mathrm{V}+\mathrm{Ti})$. One Mo-freesteel was free from molybdenum, while the second $0.15 \%$ Mo-steel contained $0.15 \%$ molybdenum. Both steels were characterized by high purity of harmful impurities $(\mathrm{S}=0.001 \%$ and $\mathrm{P}=0.010 \%)$, and the nonmetallic inclusions. Plates $20 \mathrm{~mm}$ thick were thermomechanically processed at reversing plate mill by the controlled rolling technology followed by cooling from the austenite field at a rate of more than $20^{\circ} \mathrm{C} / \mathrm{s}$ to a temperature ranging from 410 to $565^{\circ} \mathrm{C}$.

Fig. 1 shows the effect of the finish temperature of accelerated cooling $\left(\mathrm{T}_{\mathrm{fc}}\right)$ on the strength properties of the plates. As $\mathrm{T}_{\mathrm{fc}}$ decreases from 565 to $420^{\circ} \mathrm{C}$, the average yield strength increases by $30 \mathrm{~N} / \mathrm{mm}^{2}$ from 440 to 470 $\mathrm{N} / \mathrm{mm}^{2}$ for the steel without Mo and from 460 to 490 $\mathrm{N} / \mathrm{mm}^{2}$ for the $0.15 \% \mathrm{Mo}$-steel. The increase in the ultimate tensile strength was $50-55 \mathrm{~N} / \mathrm{mm}^{2}$ : from 525 to $580 \mathrm{~N} / \mathrm{mm}^{2}$ and from 550 to $600 \mathrm{~N} / \mathrm{mm}^{2}$ for steels without Mo and with $0.15 \% \mathrm{Mo}$, respectively. The average yield strength and tensile strength of the plates from the steel with $0.15 \%$ Mo were by about $20 \mathrm{~N} / \mathrm{mm}^{2}$ higher than those of the steel without Mo [1,2].

\footnotetext{
* Corresponding author: kholodnyi.aa@gmail.com
} 


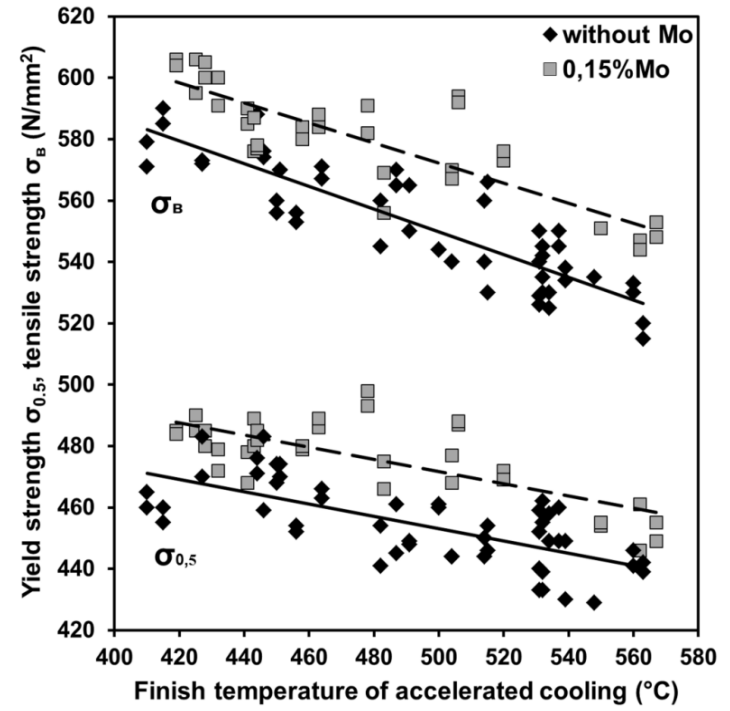

Fig. 1. The effect of the finish temperature of accelerated cooling on the yield strength and tensile strength of plates from the Mo-free-steel and $0.15 \% \mathrm{Mo}$-steel

\subsection{Microstructure}

Fig. 2 shows the microstructure of the centerline segregation zone of plates after accelerated cooling to $420^{\circ} \mathrm{C}$. In the axial zone of the plate from the steel with $0.15 \% \mathrm{Mo}$, the segregation bands contained regions of twinned high-carbon martensite with retained austenite (MA constituent). The segregation bands consisting of coarse packets of acicular bainitic ferrite with interlayers of retained austenite are present at the lath boundaries in the axial zone of the Mo-free-steel plate. The structure of the axial zone of plates from both steels after cooling to $560^{\circ} \mathrm{C}$ also consisted of MA.

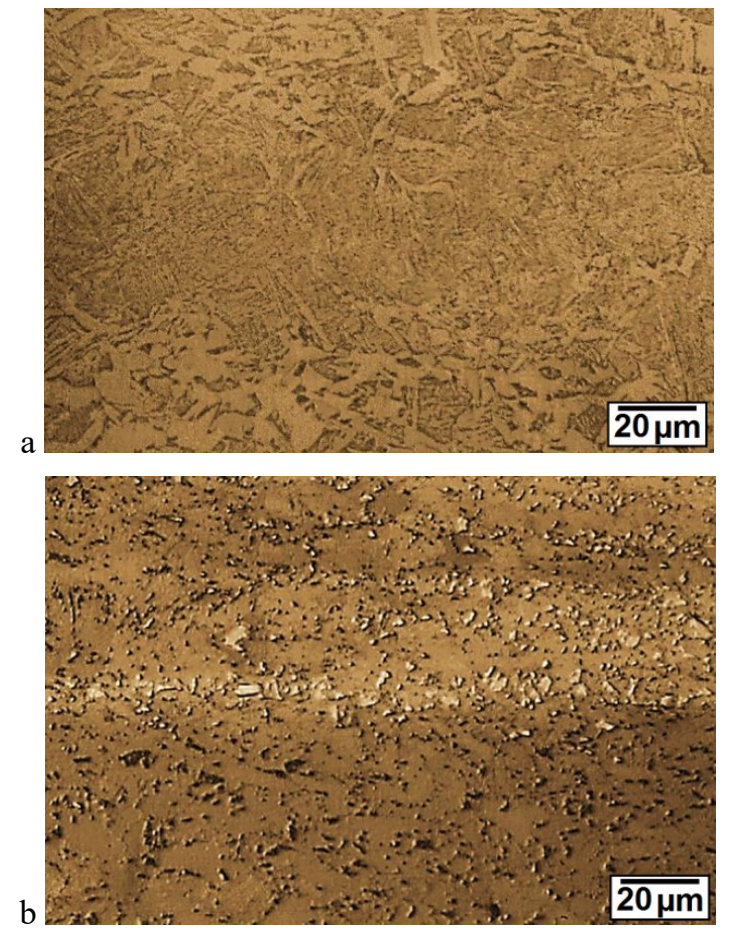

Fig. 2. The microstructure of the centerline segregation zone of the Mo-free-steel (a) and $0.15 \% \mathrm{Mo}$-steel (b) plates after accelerated cooling at $420^{\circ} \mathrm{C}$, OM (etching in LePera reagent)

\subsection{Resistance to hydrogen induced cracking}

Such change in the microstructure of the segregation bands in the plates affected their HIC resistance (fig. 3). A decrease in the finish temperature of accelerated cooling of the molybdenum-free steel plates from 565 to $420^{\circ} \mathrm{C}$ deteriorates their HIC resistance as follows: CLR increases from $0 \%$ to about $17 \%$. The molybdenumcontaining plates rapidly cooled to $\mathrm{T}_{\mathrm{fc}}$ ranging from 560 to $420^{\circ} \mathrm{C}$ did not exhibit any substantial change in the HIC resistance. The average CLR parameter of the steel plates with $0.15 \%$ Mo after accelerated cooling to different $\mathrm{T}_{\mathrm{fc}}$ in the range under consideration was about $1 \%$. The hydrogen-induced cracks propagate in the axial zone along the segregation bands. The plates with segregation bands in the axial zone with regions of the MA constituent exhibited a substantially higher HIC resistance than the plates with segregation bands consisting of coarse packets of acicular bainitic ferrite with interlayers of retained austenite at the lath boundaries $[1,2]$.
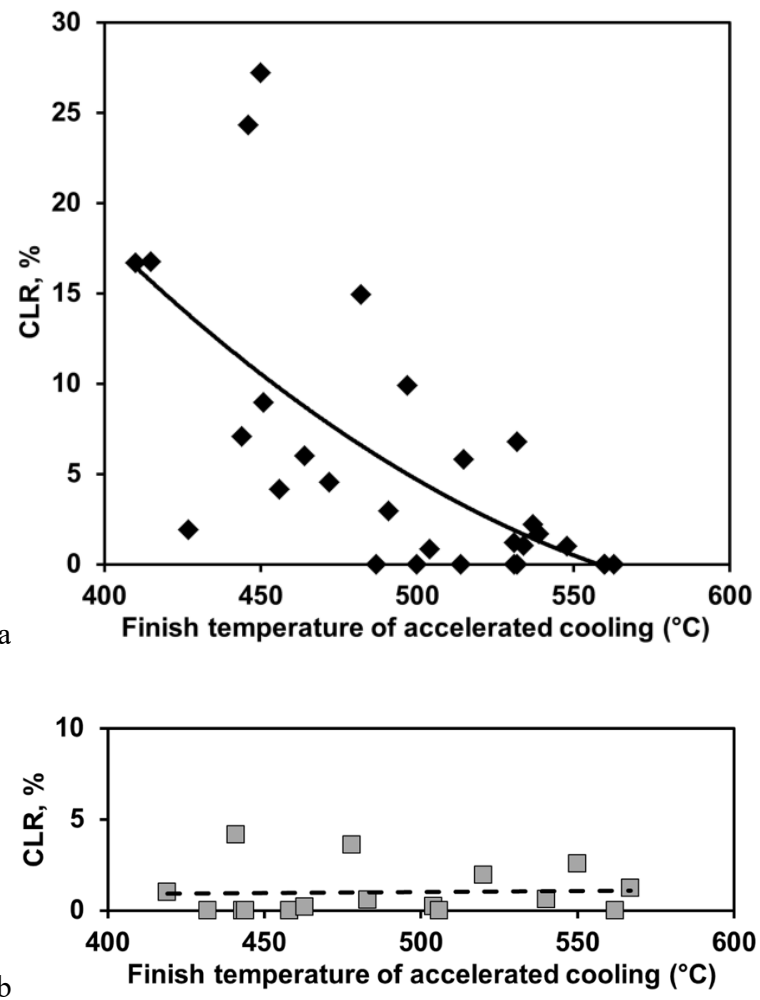

Fig. 3. Effect of the finish temperature of accelerated cooling on the crack length ratio of the plates from the Mo-free-steel (a) and 0.15\%Mo-steel (b)

Thus, the addition of $0.15 \%$ Mo into the steel increases the HIC resistance of the plates as the finish temperature of the accelerated cooling decreases from 560 to $420^{\circ} \mathrm{C}$. Simultaneously, there is a substantial increase in strength properties: the yield strength increases by $50 \mathrm{~N} / \mathrm{mm}^{2}$, and the tensile strength increases by $75 \mathrm{~N} / \mathrm{mm}^{2}[1,2]$. 


\section{Effect of heating in $\alpha-,(\alpha+y)-$ and $y$ - regions}

The influence of heating in the $\alpha-,(\alpha+\gamma)$ - and $\gamma$-regions followed by air cooling on the strength properties and resistance to HIC of various alloying systems and grades pipe steels plates was studied:

- steel 1 (X56): $0.05 \% \mathrm{C}-0.65 \% \mathrm{Mn}-0.54 \% \mathrm{Cr}-0.12 \% \mathrm{Ni}-$ $0.11 \% \mathrm{Cu}$;

- steel 2 (X70): 0.10\%C-1.64\%Mn;

- steel 3 (X80): 0.07\%C-1.75\%Mn-0.22\%Ni-0.22\%Mo.

All steels contained: $\mathrm{Si}=0.19-0.32 \% ; \mathrm{P} \leq 0.010 \%$; $\mathrm{Ti}=0.018-0.025 \% ; \mathrm{Al}=0.034-0.040 \% ; \mathrm{N} \leq 0.008 \%$; $\mathrm{Ti}+\mathrm{Nb}+\mathrm{V} \leq 0,15 \%$.

Plates with a thickness of $12 \mathrm{~mm}$ were manufactured using technology controlled rolling with followed accelerated cooling from austenitic region with rate of $15-25^{\circ} \mathrm{C} / \mathrm{s}$ to temperatures of $550-575^{\circ} \mathrm{C}$. Heat treatment was carried out at temperatures from 200 to $950^{\circ} \mathrm{C}$ and further air cooling.

\subsection{Strength properties}

The influence of heating on the strength properties is shown in fig. 4 . The average values of yield strength and tensile strength of plates after controlled rolling with accelerated cooling are follows:

- steel 1 (X56): $\sigma_{0.2}=405 \mathrm{~N} / \mathrm{mm}^{2} ; \sigma_{\mathrm{B}}=508 \mathrm{~N} / \mathrm{mm}^{2}$;

- steel 2 (X70): $\sigma_{0.2}=575 \mathrm{~N} / \mathrm{mm}^{2} ; \sigma_{\mathrm{B}}=665 \mathrm{~N} / \mathrm{mm}^{2}$;

- steel 3 (X80): $\sigma_{0.2}=610 \mathrm{~N} / \mathrm{mm}^{2} ; \sigma_{\mathrm{B}}=700 \mathrm{~N} / \mathrm{mm}^{2}$.

The tempering of plates (heating in $\alpha$-region) at temperatures of $200-400^{\circ} \mathrm{C}$ has led to an increase of steels strength properties. Heating at temperatures of $500-600{ }^{\circ} \mathrm{C}$ for steel $2(\mathrm{X} 70)$ and at $500^{\circ} \mathrm{C}$ for steel 3 (X80) resulted in a decrease of strength properties to a level comparable to the level of steel strength after TMCP. A further increase in tempering temperature contributed to an increase in the strength properties of all steels.

The maximum increase in strength properties of plates after tempering are follows:

- steel 1 (X56): $\Delta \sigma_{0.2}=50 \mathrm{~N} / \mathrm{mm}^{2}$ и $\Delta \sigma_{\text {В }}=60 \mathrm{~N} / \mathrm{mm}^{2}$;

- steel 2 (X70): $\Delta \sigma_{0.2}=40 \mathrm{~N} / \mathrm{mm}^{2}$ и $\Delta \sigma_{\mathrm{B}}=95 \mathrm{~N} / \mathrm{mm}^{2}$;

- steel 3 (Х80): $\Delta \sigma_{0.2}=110 \mathrm{~N} / \mathrm{mm}^{2}$ и $\Delta \sigma_{\text {В }}=105 \mathrm{~N} / \mathrm{mm}^{2}$.

An increase in the heating temperature in the $(\alpha+\gamma)$ and $\gamma$-region led to a significant decrease in the yield strength and temporary resistance of the steel.

\subsection{Resistance to hydrogen induced cracking}

The effect of the heating temperature on the crack length ratio (CLR) of plates from the studied steels is shown in fig. 5. Plates after TMCP had different resistance to HIC (requirement: $\mathrm{CLR} \leq 15 \%$ ):

- steel 1 (X56): CLR $=0 \%$;

- steel 2 (X70): CLR $=6.1 \%$;

- steel 3 (X80): CLR $=16.8 \%$.

At tempering temperatures, no reduction in HIC resistance occurred.
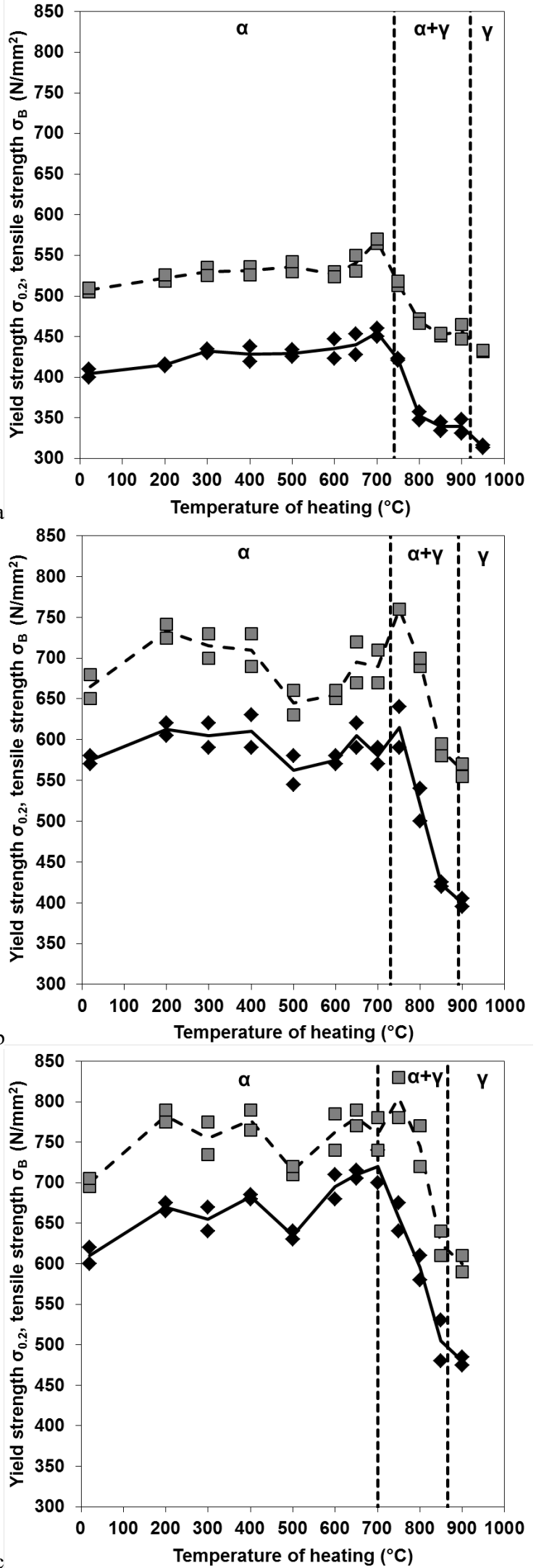

Fig. 4. Effect of heating temperature on the strength properties of the plates: a - steel 1 (X56); b - steel 2 (X70); c - steel 3 (X80) 


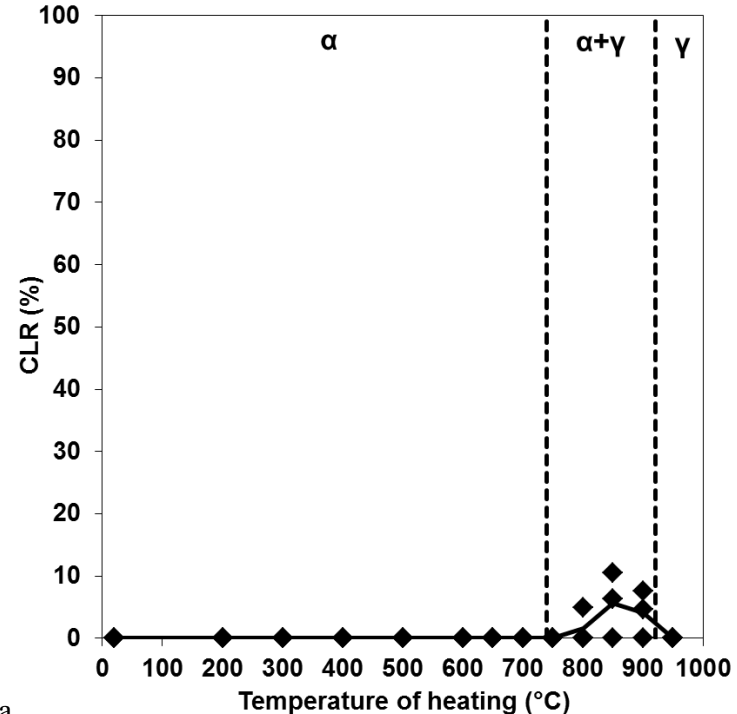

a

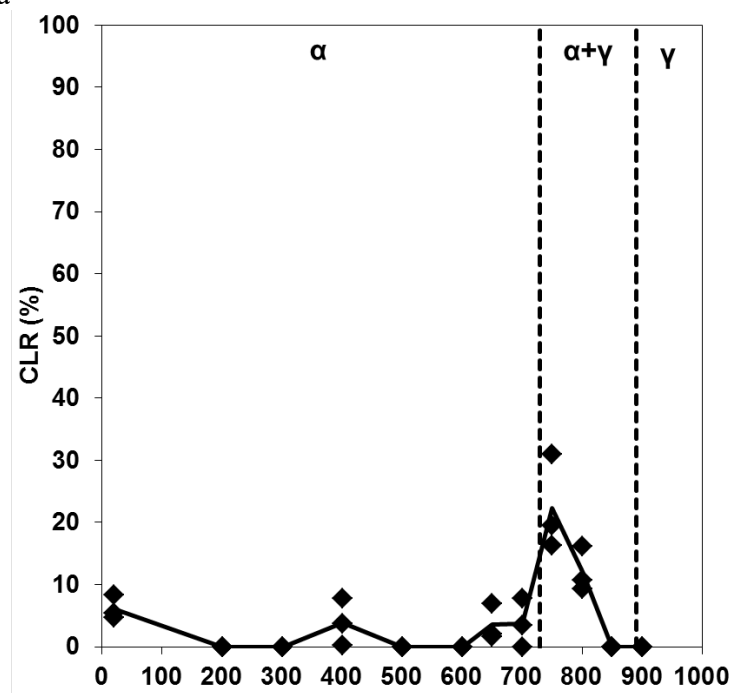

b

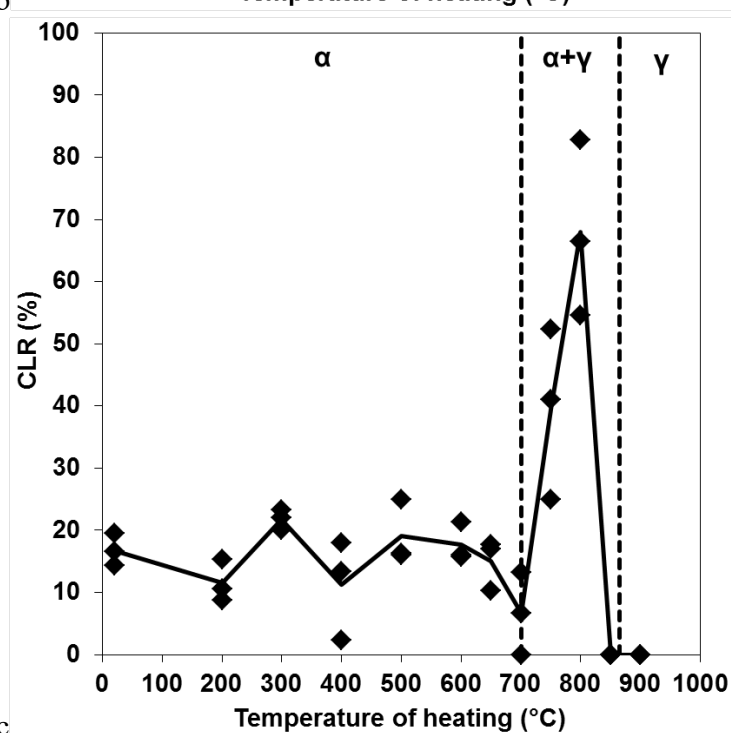

Fig. 5. Effect of heating temperature on the crack length ratio of the plates: a - steel 1 (X56); b - steel 2 (X70); c - steel 3 (X80)

Heating to the lower and middle parts of the intercritical $(\alpha+\gamma)$-region (to $800-850^{\circ} \mathrm{C}$ for steel 1 and to $750-800^{\circ} \mathrm{C}$ for steels 2 and 3 ) caused a significant decrease of plates resistance to HIC. An increase in the heating temperature to the upper part of the $(\alpha+\gamma)$-region and to the $\gamma$-region led to a significant decrease in the CLR, which at the same time reached a zero value.

Steel 1 (X56) had the highest resistance to HIC, which is explained by the low content of segregating elements - C, Mn, S and Nb. Steel 3 (X80) with the highest $\mathrm{Mn}$ and $\mathrm{S}$ content had the lowest HIC resistance.

Thus, the possibility of increasing the strength properties of steel while maintaining the initial level of resistance to HIC by using tempering of plates manufactured by controlled rolling with accelerated cooling was shown.

\section{Conclusion}

The two perspective ways to improve the strength properties and resistance to hydrogen induced cracking (HIC) of low-alloy pipe steels plates were established:

- the additive of $0.15 \%$ molybdenum while decreasing finish temperature of accelerated cooling from 560 to $420^{\circ} \mathrm{C}$;

- the use of tempering at heating in the $\alpha$-region.

\section{References}

1. I. Shabalov, Y. Matrosov, A. Kholodnyi. et al., Pipeline Steels for Sour Service. Springer, Cham (2019)

2. A. Kholodnyi, Yu. Matrosov, S. Sosin, Metallurgist 61, 230-237 (2017) 